\title{
Generalization of habituation of the GSR to white noise of varying intensities'
}

\section{J. P. JAMES and G. R. HUGHES, University of Manitoba, Winnipeg, Canada}

Two groups, each consisting of 40 university students, were given eight habituation trials of a $2-\mathrm{sec}$ white noise at a mean intertrial interval of 1 min. One group received a 67-dB stimulus, the other a 76-dB stimulus. On Trials 9-12, $20 \mathrm{Ss}$ from each group were tested for stimulus generalization at intensities of 70 or $73 \mathrm{~dB}$. Mean GSR on the first test trial was the measure of stimulus generalization. A reliable upwardsloping generalization gradient to increases in stimulus intensities and a trend for a downward-sloping gradient to decreases in intensities were found.

An orienting response (OR) is evoked by a novel change in stimulation of a sufficient magnitude and will diminish in strength upon repeated presentations of this stimulus change. The process whereby the magnitude of the OR decreases is termed habituation. Several investigators (e.g., Sharpless \& Jasper, 1956, p. 678) have emphasized that habituation is specific to the stimulus. Studies investigating the extent of such specificity are those concerned with the stimulus generalization of habituation (Corman, 1967; Williams, 1963). Corman (1967) .obtained symmetrical generalization gradients ta tonal test stimuli of either higher or lower frequencies than the habituated stimulus.

- The present study set out to investigate the nature of stimulus-intensity generalization of habituation within a narrow segment of the intensity continuum. A limited range of intensities was employed to insure that Ss habituated to the extreme intensities (low or high) would not differ in rate of habituation or level of arousal.

It was thought at the outset that, following habituation to a stimulus of a given intensity, increases in stimulus intensity would facilitate the $O R$ in an amount directly related to the extent of the change. A similar enhancement of the habituated $O R$ to decreases in signal intensity would be expected on the basis of Sokolov's (1960, p. 205) well-known finding that, following habituation to a stimulus of a given intensity, lower stimulus intensities will re-evoke the OR.

\section{SUBJECTS}

The Ss were 99 undergraduate students from the introductory psychology course at the University of Manitoba. Nineteen Ss were discarded for the following reasons: two Ss because their response exceeded 10,000 ohms, seven Ss because their base level resistance exceeded $150,000 \mathrm{ohms}$, and $10 \mathrm{Ss}$ because they met a criterion of rejection by failing to produce a response on Trials 6,7, and 8. Of these latter $S s$, five were in each of the two stimulus-intensity groups. The remaining $80 \mathrm{Ss}$ were randomly assigned to one of four groups, each consisting of 10 males and 10 females.

\section{APPARATUS}

The GSR was recorded from Fels zinc electrodes (Yellow Springs Instrument Co.), $20 \mathrm{~mm}$ diam, set in plastic cups filled with Fels electrode jelly. A Hunter CSR amplifier, modified to respond to a range of $0-150,000$ ohms, was used. The white-noise stimulus was produced by means of a Grason-Stadler 950-D generator and was presented to $S$ by Roberts earmuff-type headphones. The stimulus intensities were calibrated in $\mathrm{dB}$ at the headphones by a Bruel and Kjaer sound-level meter set on the linear fast scale (re: $.0002 \mathrm{dynes} / \mathrm{cm}^{2}$ ). The stimulus duration and interstimulus interval were controlled by a Hunter interval timer and a Gerbrands film timer, respectively. The Ss wore Lafayette blindfold goggles and were seated in a darkened room adjacent to E's room.

\section{PROCEDURE}

After being seated, the back of the S's hand was lightly sanded and a pair of goggles was placed over the eyes. The electrodes were clamped to the palm and back of the left hand. The Ss were then told that physiological responses to auditory stimuli were being measured and that white noise, described as similar to the hissing of steam, would occasionally be presented through the headphones. They were told that no shock would be given and that they were to relax, sit still, and listen. The headphones were then placed on the $S$, and the $E$ left the room.

After $2 \mathrm{~min}$ or when a relatively stable baseline resistance was established, the timer which controlled the intertrial interval was started. The 2.0-sec stimuli were programmed to occur on the average of one per minute $(45,60$, or $75 \mathrm{sec})$. In the event of a spontaneous GSR, the timer was stopped. The stimulus was then presented after the base resistance had stabilized.

The habituation phase of the experiment consisted of eight trials. Testing to the generalized stimuli occurred on Trials 9-12. Specifically, one-half of the $\mathrm{Ss}(\mathrm{N}=40)$ received eight presentations of a $67 \cdot \mathrm{dB}$ white-noise stimulus while the other half received white noise of $76 \mathrm{~dB}$. Following the eight presentations of the initial stimulus intensity each group was further divided such that one-half $(\mathrm{N}=20)$ received a $70-\mathrm{dB}$ stimulus while the other half received a 73-dB stimulus. Each group received the same stimulus intensity across the four test trials.

Skin resistance at the moment of stimulus onset was recorded and provided a measure of background or base level. Any deflection of the needle on the face of the GSR amplifier in excess of $200 \mathrm{ohms}$ which occurred from $1.5 \mathrm{sec}$ after stimulus onset was recorded by $E$. These scores were converted to log conductance change and analyzed by means of analysis of variance (ANOVA).

\section{RESULTS AND DISCUSSION}

Figure 1 presents mean GSR magnitudes as log conductance change for groups habituated to stimulus intensities of 67 or $76 \mathrm{~dB}$ (Trials 1-8) and tested to intensities of 70 or $73 \mathrm{~dB}$ (Trials 9-12). A Stimulus Intensity by Sex by Trials ( 2 by 2 by 8 ) ANOVA of response measures for Trials 1-8 indicated that habituation occurred equally to both stimulus intensities (Trials main effect: $\mathrm{F}=31.44, \mathrm{df}=7 / 532, \mathrm{p}<.001$; Stimulus Intensity main effect: $F<1$ ). A marginally reliable Sex by Trials interaction $(F=2.39, \mathrm{df}=7 / 532, \mathrm{p}<.05)$ and subsequent tests for simple effects indicated that female $S$ s produced greater ORs on Trial 2 while male Ss were superior on Trial $8(\mathrm{p}<.05$ for both tests). This seems to suggest that female Ss, although initially more reactive, tended to habituate more rapidly than male Ss.

Figure 2 shows the mean GSR to 67 and $76 \mathrm{~dB}$ for each group on Trial 8 and to the test stimuli, 70 and $73 \mathrm{~dB}$, on Trial 9 . An ANOVA with Direction of Change (up or down), Amount of Change ( 3 or $6 \mathrm{~dB}$ ), Sex, and Trials ( 8 or 9 ) as factors indicated one reliable effect: the Direction of Change by Trials interaction

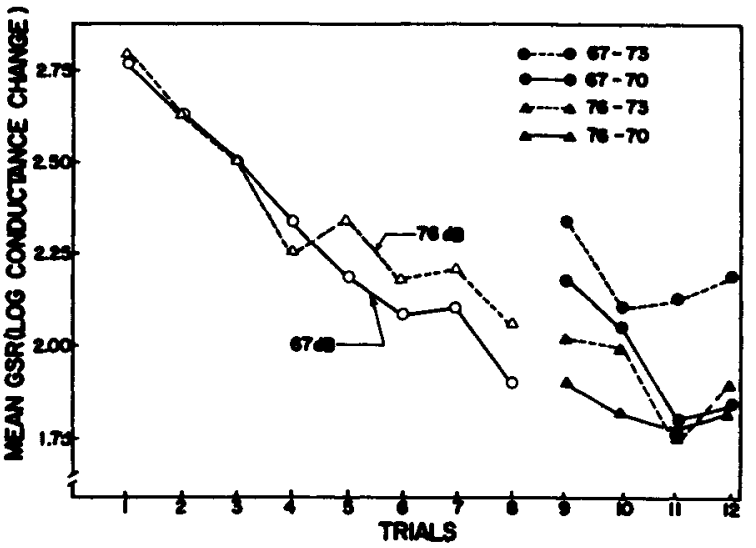

Fig. 1. Habituation of the GSR to stimulus intensities of 67 and $76 \mathrm{~dB}$ (Trials 1-8) and to test stimulus intensities of 70 and $73 \mathrm{~dB}$ (Trials 9-12). 


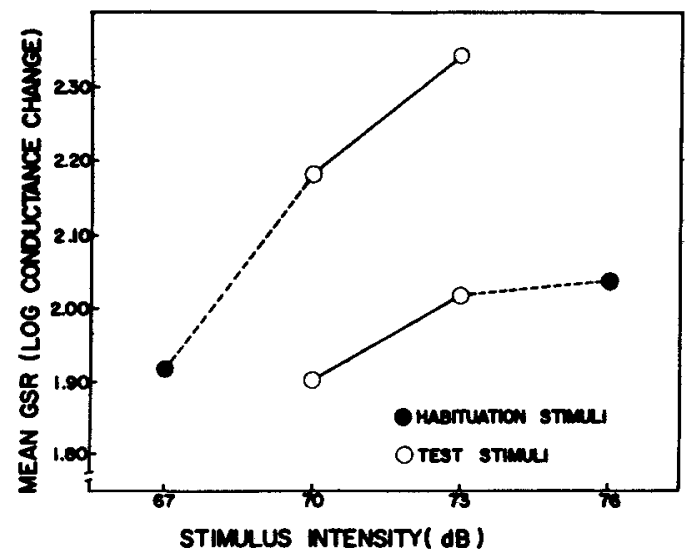

Fig. 2. Generalization gradients for increases and decreases in stimulus intensities.

$(F=8.71, \mathrm{df}=1 / 72, \mathrm{p}<.005)$. Tests for simple main effects indicated that groups habituated to $67 \mathrm{~dB}$ showed a greater magnitude of GSR on Trial 9 as compared to Trial $8(p<.005)$. The downward trend in the $76-\mathrm{dB}$ group was not reliable. On Trial 9 the mean of groups receiving the more intense test stimuli differed reliably from groups receiving the weaker test stimuli ( $p<.01)$. Thus, an increment in stimulus intensity increased the OR (decreased the effects of habituation) while a decrement in stimulus intensity had no effect.

An ANOVA conducted on the mean log scores of the test trials (9-12), including as factors Direction of Change, Amount of Change, Sex, and Trials, yielded one reliable main effect (Trials: $\mathrm{F}=3.81$, $\mathrm{df}=3 / 216, \mathrm{p}<.01$ ) and one significant interaction (Amount of Change by Sex by Trials: $F=4.02$, $\mathrm{df}=$ $3 / 216, \mathrm{p}<.01)$. The triple interaction indicates that across Trials 9-12, a 3-dB change resulted in a greater decrement in mean GSR than a $6-\mathrm{dB}$ change, and that across these trials the male Ss tended to maintain their response level while the fermale Ss showed a rapid decrement.

The analysis of base level resistance scores for Trials 1-8 indicated that although Stimulus Intensity was not reliable $(F<1)$, the Trials main effect $(F=18.68, \mathrm{df}=7 / 532, \mathrm{p}<.001)$ and the Sex by Trials interaction $(F=5.47, \mathrm{df}=7 / 532, \mathrm{p}<.01)$ were both significant. A simple main-effects analysis showed that the mean base resistance of the female $S$ s exceeded that of the male Ss on Trials 1 and $5(\mathrm{p}<.05)$ and on Trials 6-8 $(p<.001)$. The mean base resistance of the male Ss did not differ across the eight trials. The female Ss showed a significant decrement in skin resistance from Trial 1 to Trial 2 and a steady increase across Trials 2-8. Generally, these results are similar to those reported by Corman (1967) who found an overall initial drop in base resistance followed by a steady rise. The present results indicate that the steady increase over Trials $2-8$ is produced almost entirely by the female Ss. If base level resistance is indicative of general arousal or drive (the lower the resistance the higher the state of arousal), the present findings would suggest that female Ss were initially less aroused, became equal to the male Ss after the initial presentation of the stimulus, and subsequently became steadily less aroused. The male Ss, on the other hand, tended to maintain a relatively high and invariable state of arousal throughout the habituation trials.

The base resistance scores of the four test trials were analyzed in a manner similar to the GSR scores of the test trials. There was an overall significant increase in skin resistance across the test trials (Trials main effect: $F=6.20, \mathrm{df}=3 / 216, \mathrm{p}<.001$ ) and a significant Amount of Change by Trials interaction $(F=3.89$, $\mathrm{df}=3 / 216, \mathrm{p}<.01$ ). An examination of the data revealed that across Trials 9,10 , and 11 , groups receiving a 3- or 6-dB change showed a steady increment in base resistance. Across Trials 11-12 resistance continued to increase for $S s$ which received a 3-dB change, while an abrupt decrement was shown by the Ss which received the 6-dB change.

The generalization gradients shown in Fig. 2 are asymmetrical. Testing at the more intense generalized stimuli served to increase the magnitude of the OR. There was a tendency for weaker ORs when testing to stimuli of lesser intensity. At first glance, these results appear to agree with those found for stimulus-intensity generalization of CRs (e.g., Hall \& Prokasy, 1961). Following both habituation and conditioning, the response magnitude of the GSR increases to higher intensity test stimuli and decreases to lower intensity test stimuli. The effects of learning then are augmented by the stronger and reduced by the weaker generalized stimuli. But, it is clear that for habituation an inverse relationship exists. The effects of habituation are diminished by higher and tend to be enhanced by lower intensities of generalized stimuli. That is, changing to a more intense stimulus evokes ORs of greater magnitude which reduces the effects of habituation.

The present findings suggest a possible limitation to any view which assumes that change in the physical attributes of a stimulus is sufficient to produce increments in OR magnitudes. A small decrease in stimulus intensity does not affect the OR in a manner analogous to a corresponding increase in that intensity. Sokolov's (1960) well-known finding that increments in ORs follow decrements in stimulus intensity may be limited to relatively large decreases in stimulus intensity. On the basis of Kimmel's (1960) results with CRs, an increment in response strength would not be expected even for a 20-dB decrease in stimulus intensity. Further investigation using a greater range of test stimuli will reveal the nature of the generalization gradient of habituation to stronger and weaker stimuli.

\section{REFERENCES}

CORMAN, C. D. Stimulus generalization of habituation of the galvanic skin response. Journal of Experimental Psychology, 1967, 74, 236-240.

HALL, J. F., \& PROKASY, W. F. Stimulus generalization to absolutely discriminable tones. Perceptual \& Motor Skills, 1961, 12, 175-178.

KIMMEL, H. D. The relationship between direction and amount of stimulus change and amount of perceptual disparity response. Journal of Experimental Psychology, 1960, 59, 68-72.

SHARPLESS, S., \& JASPER, H. Habituation of the arousal reaction. Brain, 1956, 79, 655-680.

SOKOLOV, E. N. Neuronal models and the orienting reflex. In M. A. B. Brazier (Ed.), The central nervous system and behavior. New York: Josiah Macy, Jr., Foundation, 1960, Pp. 187-276.

WILLIAMS, J. A. Novelty, GSR, and stimulus generalization. Canadian Journal of Psychology, 1963, 17, 52-61. NOTE

1. This study was supported, in part, by a grant (APA-223) from the National Research Council of Canada. The results were presented at the 1968 meeting of the Rocky Mountain Psychological Association, Denver, Colorado. 